Acta Universitatis Wratislaviensis No 3920

Anglica Wratislaviensia LVII, Wrocław 2019

DOI: 10.19195/0301-7966.57.16

Francisco J. Álvarez Gil

ORCID: 0000-0002-8752-9091

University of Las Palmas de Gran Canaria

franalvarezgil@gmail.com

\title{
Review of Beyond the Universe of Languages for Specific Purposes: The 21st Century Perspective, Mary Frances Litzler, Jesús García Laborda and Cristina Tejedor Martínez (eds.), Madrid: Servicio de publicaciones de la Universidad de Alcalá, 2016
}

This manual contains worthy material in relation to the field of Language for Specific Purposes (LSP). It comprises 29 papers dealing with relevant topics in LSP. The papers are divided into three different categories, namely, (1) teaching, (2) linguistics, and (3) translation. A "Foreword" by the editors precedes these papers. All the studies included in this volume focus on the analysis of specialized discourse in English and Spanish, and most of them include corpus methodology in which the use of technology is integrated.

The section devoted the teaching of LSPS contains varied topics comprising the implementation of teaching models and approaches by offering new perspectives, some of which derive from the authors' actual observation of practice and teaching experiments. The paper by Manuela Crespo describes the Eurocrea project, which was run in different Spanish and Belgian universities, and it focuses on the use of teleconferences to practice oral skills using a task-based approach in a synchronous computer-mediated communication environment. The empirical side of this contribution reports on a survey taken by participating students to reveal Eurocrea approach's motivational value and its benefits when it comes to learning languages in context, as learners from different countries may improve their oral linguistic skills through virtual interaction. Obviously, the number of informants, all of them from the University of Antwerp, is quite limited, and so the conclusions drawn from their answers should be taken as provisional, as the author herself 
admits. The contribution by Francisco Rubio Cuenca describes learning through the use of wikis, as this tool allows for the practice of different language skills. His paper revolves around experience gathered during four years of practising the use of Moodle wikis.

The following paper by García Esteban deals with intercultural competence development through the use of video technology at tertiary level. This is also research done within the framework of a larger project, i.e. REDTELECOM. Her research reveals that the use of video technology is advantageous enough to promote both collaborative learning and autonomous learning. The description of the data and method offers some information concerning the number of participants, their degree and the procedure carried out to accomplish the research, but I would like to also find some reference to the sociological aspects in relation to the participants. The theoretical framework is certainly very complete for a paper of this length; however, a more detailed description of the methodology followed would have enriched the study.

Dr. Alberola Colomar describes research conducted with university students studying for degrees in Tourism and Primary Education at Florida Universitaria measuring their motivation in longer class projects. The research is well described and organized, all arguments in the discussion section being supported by quantitative evidence. The complete paper constitutes a proposal, as manifestly indicated in the title. The final section heading also includes the word "recommendations", i.e. "Conclusions and recommendations". Despite these indicators, no recommendations are listed in this part of the article, although the reader may easily infer good ones from the reading of the paper, and especially from the concluding remarks. The paper by Barreiro Elorza and Sancho Guinda describes a long term CLIL experience at Universidad Politécnica de Madrid for the promotion of sci-tech innovation. Their work deals with genre and styles, and students learn to become autonomous in a real environment after training developed in a designed workshop, where they acquire minimal competences in this respect. The result is a simultaneous contribution between communication and technology. The complete venture, as the authors themselves named their research and experiment, leaves a number of questions concerning CLIL assumptions that the authors propose for further consideration. Altogether, this is high-quality research and represents an excellent contribution for LSP teaching and learning, as it shows how linguistic knowledge and technology can be integrated to provide professional results. Similarly to what has been done in historical pragmatics, the authors evince the way in which the evolution of scientific thought goes hand-in-hand with the evolution of scientific thought-styles. A different issue related to CLIL teaching is covered in Bellés-Fortuño and Ferrer Alcantud's paper. They present a teaching example, and this is related to the use of English for teaching university content courses in the humanities other than English language, literature and culture. The authors propose the use of innovative and visual material in order to make courses attractive. This type of material, e.g. television series on history, allows students to study the 
language in a given context while assessing the quality of the contents offered. The paper also informs on how anxiety has a clear impact on the students' learning and progress, and reveals aspects which can be covered in the classroom, thus reducing this level of anxiety.

The chapter by Torregrosa and Sánchez-Reyes reports on problem-oriented policing methodologies; an approach first coined by Goldstein (1979), and how these are accommodated in a course of English for Law Enforcement. The topic is not really new but interesting enough to be included in a volume like this one. My reservations concern the way in which the information is presented in this paper, as much of the content has deontic descriptions of procedure, and these are not always justified. The work is marred by value-laden words assessing the effectiveness of the methodologies proposed without empirical evidence being given. The conclusion section reads "1. Conclusions" rather than "5. Conclusions". Be that as it may, concluding remarks are not given at this stage, and they are finally offered in section 4, instead. Rábano Llamas and Hernández Barriopedro's paper is also a very fine and well-documented piece of writing. In the case of Santamaría's paper, their work is wrongly placed, and should be in the linguistics section, as it does not really deal with teaching LSPs. Their research enhances the use of text-to-speech recognition technology from earlier stages in learning L2 sounds, together with phonemic awareness, in order to improve students' performance, with interactive activities seeking to increase the learners' motivation.

Dr. Ruggeiero's contribution describes the project Creating Communities, Engaged Scholarship (CruCES) developed at the University of Memphis (USA), in which the relationship between Community Service Learning and Intercultural Sensitivity Development is studied. The results, following from learning Spanish for Specific Purposes in context (e.g. Caritas Village in Memphis) are clear and show an increase in the students' Intercultural Sensitivity Development among other results. In total, there is much work to be done to evaluate the findings obtained for the CruCES project, as indicated in the participants' journal entries, digital photographs, and survey results, and as noted by the author in her conclusion section. The last paper of this section is a contribution by Curado Fuentes. The topic revolves around grammatical development by using data-driven learning. The experiment carried out includes two groups of students from the joint degree of Business and Tourism at the Universidad de Extremadura, one using data-driven learning techniques and the other one following a more traditional approach. The paper is well structured and informative enough to let readers understand the procedure used to develop the experiment, even if a specific section for the description of data and participants is missing. All this information is, however, given in other places within the article. The results are revealing and strongly supported by statistics. In general, the paper concludes that the data-drive learning techniques seem to be more stimulating and instructive than the use of traditional textbooks for the study of grammar points. Surely, Curado's findings are in line with what other 
LSP instructors have felt when designing and using class activities based on large specialised corpora (both synchronic and diachronic) and corpus tools with students to build new knowledge. This way of learning demands much critical attitude from learners, as they need to construct their knowledge from real examples, and this requires a great deal of analysis and introspection, among other experiential and cognitive processes.

The second part of the book is entitled "Linguistics", and is a collection of nine papers, one of which is in French. The specific topics and languages of application might be numerous but, in this volume, they mainly fall in the area of the lexicon and the semantics of Spanish, English and French. The first of these is written by Narvajas Colón, and deals with the way in which learning Spanish vocabulary in the field of economics strengthens students' communicative competence in this language, and this includes the study of collocations, as evinced in certain corpora. The paper is really ambitious, and that is clearly seen in the selected corpora listed in section 3, page 72. I would have preferred a more thorough description of each, even if these compilations are familiar to a specialist in corpus linguistics and in Spanish. I would need to know the reason why a historical corpus, i.e. the Corpus diacrónico del español (CORDE), is of interest to L2 learners of Spanish for financial purposes, or the like. Although I find variation and change attractive, I cannot see the point in teaching a learner non-standard or old-fashioned words (cf. page 72, examples guita, parné and cuartos). The section on metaphor is also very engaging, but I think this really represents a different study and deserves a paper in itself. As it stands, the paper comprises far too many distinct aspects (vocabulary learning, collocations, and metaphor in journalistic genres) in an attempt to show how lexical and semantic competence in Spanish for business can be improved at tertiary level in Germany. In the concluding section, some aspects are left unresolved, specifically some concerning intercultural competence, which may be considered the departure point for future research.

A contrastive study (German-Spanish) in the field of medicine is offered in the following contribution by Burgos Cuadrillero and Rohan Schrade. They concentrate on word-formation processes as a way of teaching and learning terminology. Their conclusions deal with patterns of use and how register plays an important role in facilitating comprehension in the targeted language. That is especially the case with German; this language presents more cases of synonyms following Germanic word-formation processes to allow comprehension to native speakers who are unlikely to understand the Greek or Latin roots, suffixes and prefixes. López Zurita focuses on English terms used in content courses in the Degree of Marketing at the Universidad de Cádiz. This borrowed terminology appears to be frequent in some marketing content courses delivered in Spanish. Other courses do not present interference from English. The conclusions reveal that, except for some specific cases, there is some abuse of English terms, as Spanish has equivalents for these. Precisely, the term marketing and its influence on Spanish political discourse are 
central in Isabel Negro's contribution. The paper seeks to find out how the creation of a brand as applied to political parties in Spain is constructed in the vernacular. The topic is well justified, and the selection of corpus is described, but details concerning length of corpus, data management, representativeness, and text retrieval and analysis, among others, are missing. Results have been arranged according to function, either in discourse or in society, in which concepts related to genre and register are at the core of the use of specific terminology to build a discourse to present a political party as a brand.

Vazquez Amador and Lario de Oñate present a sociolinguistic survey performed on Spanish celebrity magazines in order to detect linguistic borrowings. My major concern with this paper is the gathering of the corpus and how it has been interrogated for analysis and text retrieval. There is no information on which statistics could be raised either, among other fundamental features in corpus making and use, e.g. corpus length. The distinction between a loanword and a borrowing is maybe not that clearly stated although it is quite important insofar as some foreign words, already codified in the DRAE, may appear to be so familiar to a Spanish reader. I therefore wonder whether it makes sense to consider them in a study of this type (e.g. tul, appearing in La quimera (1905) by Emilia Pardo Bazán, and even earlier). The paper by Quijano and Westall examines Spanish journalistic discourse to find out ways in which Colombians are depicted. The reader will find detailed information concerning the corpus in section 2 . The conclusions indicate that Spanish newspapers still seem to reflect an imbalance in the power relationship in which the Colombian people are referred to in the same traditional terms related to crime rather than focusing on other more positive aspects.

The following papers by Durán Escribano and Argüelles Álvarez, and Molina Plaza focus on metaphorical language. Durán Escribano and Argüelles report on cross-disciplinary metaphorical meaning extensions and the creation of new terms to conceptualize scientific phenomena. Molina Plaza studies metaphors from a multimodal perspective on technical discourse of wine in Spanish. The results of these two studies have direct applications for the study of technical and scientific languages, and especially for improving understanding of L2 texts. The last paper in this section, written in French by Dogoriti and Vyzas, reports on the use of word clouds with a didactic scope, as the visualization of these clouds reflects the contents of texts, and this has a mnemonic effect for students. The experiment was carried out with French students of translation of Greek legal texts being the target language. This paper seems to be better suited to the next section, devoted to the translation of LSP.

The last section of papers is devoted to the field of translation, and it contains another set of nine papers. Santamaría Urbieta covers the aspect of mood in the translation of English guidebooks into Spanish. The author analyzes the way in which the English imperative mood is rendered into Spanish. Although the references included are manifestly relevant to this topic, I would also recommend 
including some studies concerning the study of mood and modality, among which I would include Palmer (1998) and Nuyts and van der Auwera (2016). Statistics are clearly indicated in section 3 of the paper. I would also doubt whether some of the examples, such as "véase" as the Spanish rendering for the imperative form "see", for example, should be interpreted in terms of interpersonal distance, as this form has been somehow institutionalized in this context. In English, I am not sure either that writers purposively use the imperative mood with an intention to be more direct and thus to shorten the interpersonal distance between them and their audience, even if the form you can be retrieved from context. The imperative mood is traditionally related to expositive texts to indicate directions, and this text type is present in the guidebook genre. It would then, perhaps, be a good idea to take a new path, and so Santamaría Urbieta should consider the textual genre variable (and also the text-type variable) in her analysis of comparable corpora. The following paper by Montemayor-Borsinger explores the concept of effectiveness in a corpus of translated versions of the same abstract, following a systemic-functional linguistics framework. The paper is very well written and documented, and nicely illustrated with evidence excerpted from her corpus. Conclusions drawn from her analysis have pedagogical implications, as suggested by the author.

Okoniewska's paper is another study dealing with teaching that is misleadingly located in the linguistics section. The paper deals with teaching conference interpreting following a Critical Discourse Analysis approach. It is a successful preliminary approach, and, in this context, it is justifiable that the amount of evidence used is so limited, i.e. a fragment of a speech from a well-known Spanish politician. Valero-Garcés presents a study related to the lexical influence of eurolects on Spanish legal texts. The description of the corpus is correct, even if the exact number of words per group of texts to make data comparable after the normalization of figures is missing. The discussion and conclusion sections lack statistical information regarding findings to support the author's claims. In the same section, we can find the paper by Martínez Mateo, which focused attention on giving parameters for measuring quality in professional translation.

Zaretskaya's paper is an excellent contribution and offers a detailed and accurate evaluation of computer-assisted translation tools. The article by Serra Pfennig presents the author's reflections concerning the translation problems translators have to face when they need to render new innovations in the target text. For this, the author revises the concept of specialized language in German and offers a complete list of references. Lucía Gómez's paper shows interesting technical information concerning a videogame designed in Java for teaching English. The cognitive study developed in Cortés de los Ríos and Bretones Callejas is the last paper in this section. It explores the use of mental schemes and representations as suggested in car adverts in Iberia Ronda Magazine. This is not made explicit in the corpus description, unless the authors had focused on the adverts included in this in-flight magazine and possible renderings in a second language there included. 
I do not want to end this review without a final word of admiration for the contributions of the authors of this publication to the field of LSP. Their research summaries dealing with (1) teaching, (2) linguistics, and (3) translation are, in general terms, quite illustrative of ongoing research projects in the field. Some typical editorial blunders can, however, be found. One formatting aspect that should be revised, apart from the placement of section headings in running text, is greater coherence in the use of quoting conventions, as there are different ones and some appear to be incomplete. Finally, as a reader, I would have expected a much clearer introductory section devoted to the presentation of contents than the information that was included in the prefatory material. Apart from these issues, I have no other reservations about recommending its reading and use. I enjoyed all the articles, especially those touching on discourse aspects of LSP texts and their didactics.

\section{References}

Goldstein, H. 1979. "Improving Policing: A Problem-Oriented Approach." Crime and Delinquency 25.2. 236-243.

Nuyts, J., and J. van der Auwera (eds.). 2014. The Oxford Handbook of Modality and Mood. Oxford: Oxford UP.

Palmer, F. R. 1998. Mood and Modality. New York: Cambridge UP.

Pardo Bazán, E. 2012. La quimera. Alicante: Biblioteca Virtual Miguel de Cervantes. Retrieved from http://www.cervantesvirtual.com/nd/ark:/59851/bmcsx684. 25 Nov. 2017. 